\title{
IODiCUS - Smart Balancing of Local Energy Demand
}

\author{
Dan Schien, Paul Shabajee, John Brenton, Chris Jones, Chris Preist \\ Department of Computer Science \\ University of Bristol \\ UK \\ \{daniel.schien,paul.shabajee,john.brenton,chris.jones,chris.preist\}@bristol.ac.uk
}

\section{Keywords-Building Energy, BMS; IoT; sustainability;}

\section{ConteXt AND Motivation}

For electric utility companies variability of demand for electricity results in disproportionately high cost for services consumed only for a small duration of the day.

High peak demand means:

- More power plants and network infrastructure must be available to supply these peaks.

- 'Dispatchable' energy sources used to meet peaks are often less efficient gas plants and, increasingly, diesel generation with a higher carbon intensity than alternatives.

- Use (and storage) of local renewable and low carbon energy.

Utility companies try to encourage reduced use by customers at peak times using premium prices (DUOS and TRIADS).

Energy managers in customer organisations can respond by smoothing demand on external electricity supply through:

- $\quad$ Short time energy buffering/storing (boosting).

- Rationing of services at peak times.

- Use (and storage) of local renewable electricity.

The IODICUS project is developing an intelligent, autonomous control of a customer campus electricity system with the potential to:

- $\quad$ Reduce peak power demand

- Reduce overall electricity consumption

- Make optimal use of local renewable generation

\section{Methodolgy}

As part of the IODiCUS a team of partners have developed a system to enable the effective balancing of electricity demand.
The system is deployed on several sites around the campus of the UoB, including student accommodation and offices.

The project partners are constructing a system of sensors and actuators inside the buildings, a middleware to aggregate device and contextual information (such as solar electricity generation data) and an algorithm to optimise the balancing of demand per site.

Example interventions include:

- 'Overheating' water before the peak periods, and then not heating it during them unless temp goes below acceptable limit.

- Switching off or dimming lights more quickly when motion sensor detects nothing.

- $\quad$ Alternating the heating of rooms (in 15 second bursts) to 'cap' the overall power consumption of the heating system.

\section{OPEN RESEARCH QUESTIONS}

What are the most effective strategies for an automated system to balance electricity demand?

What factors influence the potential to balance electricity consumption most strongly?

What is the potential for such a system to reduce electricity consumption?

How do residents respond to autonomous changes of electricity services?

And how does their expectation of the level of service change in response to the design of the interaction with the system?

\section{REFERENCES}

[1] IODiCUS Project http://www.iodicus.org/. IODiCUS is funded by Innovate UK 